\title{
THỰC TRẠNG LOGISTICS VIẸTT NAM TRƯỚC VÀ TRONG ĐẠI DỊCH COVID-19
}

\author{
Nguyễn Ý Nhi, Lê Ngân Phương, Nguyễn Thu Phương, \\ Nguyễn Minh Quang, Ngô Việt Quân
}

Đại học Quốc gia Hà Nội

Ngày 04 tháng 02 năm 2022

Preprint DOI: 10.31219/osf.io/yh4x7

Ngành Logistics ngày càng đóng một vai trò quan trọng trong toàn bộ quá trình hoạt động của xã hội, đặc biệt là trong sản xuất, lưu thông và phân phối các sản phẩm và dịch vụ. Tại Việt nam, theo số liệu thống kê, dịch vụ Logistics chiếm khoảng từ 15$20 \%$ GDP. Như vậy, có thể thấy, hoạt động Logistics mang lại giá trị to lớn cho nền kinh tế của quốc gia. Tuy nhiên trong hai năm trở lại đây, ngành Logistics có nhiều sự biến động vì sự bùng phát của đại dịch COVID-19. Vì ảnh hưởng của dịch bệnh mà ngành Logistics gặp rất nhiều khó khăn trong việc vận tải hàng hóa, cụ thể, theo số liệu thống kê thì ngành vận tải hàng hóa đã chịu tác động không nhỏ trong tình hình dịch bệnh, số lượng luân chuyển hàng hóa đã có sự giảm sút. Ngoài ra, dịch bệnh cũng gây ảnh hưởng đến hoạt động đào tạo nguồn nhân lực của các doanh nghiệp. 


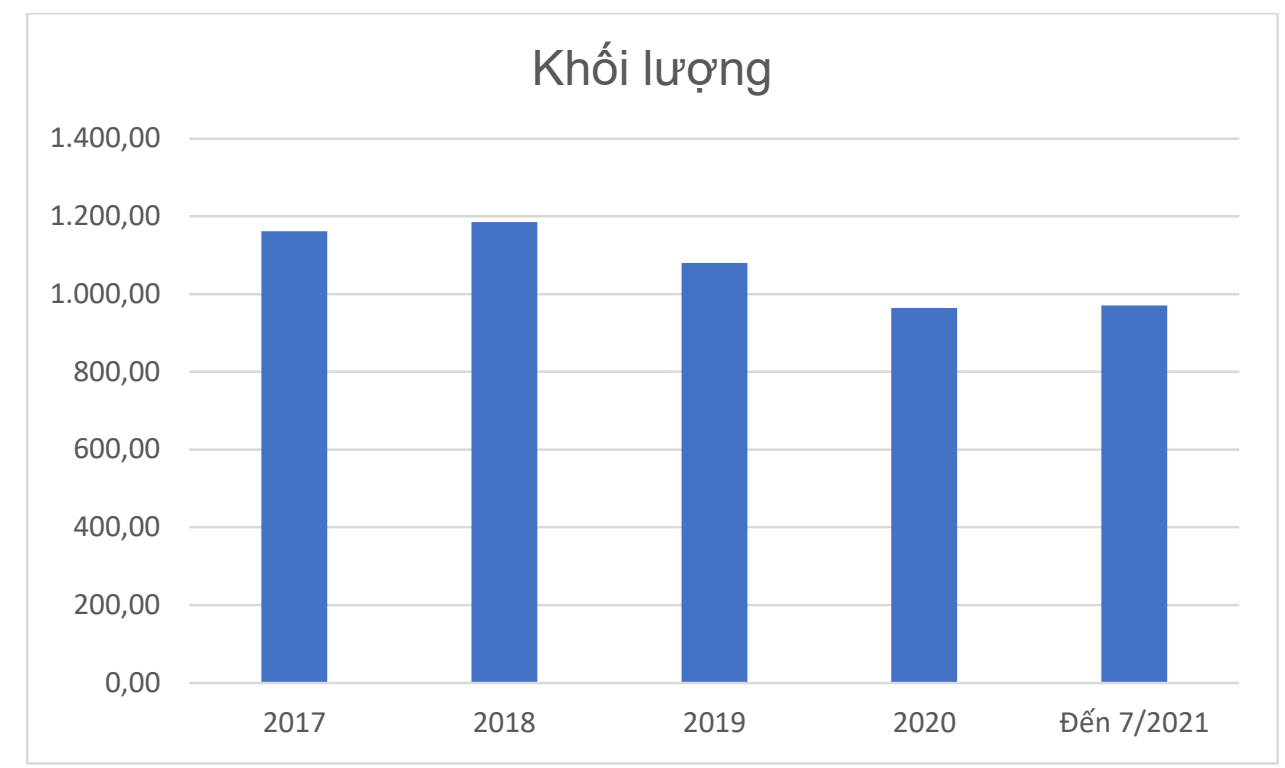

Hình 1. Khối lượng vận tải hàng hóa trong nước năm 2017- 7/2021

(Đơn vị: triệu tấn)

\section{Nguồn: Báo cáo Logistics Việt Nam - Bộ Công Thuơng}

Bên cạnh những bất lợi, đại dịch COVID-19 vẫn có những tác động tích cực và đóng góp một phần không nhỏ vào quá trình thúc đẩy ngành Logistics Việt Nam phát triển.

\section{Khái quát chung về Logistics}

\section{Khái niệm Logistics}

Khái niệm hậu cần/ Logistics liên quan tới kinh doanh ra đời từ những năm 1950, là hoạt động vận chuyển, lưu kho và cung cấp hàng hóa. Trong kinh doanh, Logistics có thể hiểu là sự tập trung của cả nguồn lực bên trong lẫn bên ngoài bao gồm cả quá trình chuyển từ "người sản xuất", qua nhiều giai đoạn và đích đến là "người tiêu dùng cuối cùng”. Logistics là quá trình lập kế hoạch, thực hiện và kiểm soát việc di chuyển và lưu trữ nguyên vật liệu, sản phẩm trong quy trình, thành phẩm và các thông tin liên quan từ khâu thu mua nguyên vật liệu đến khi tiêu thụ nhằm đáp ứng nhu cầu của người tiêu dùng. Nói một cách đơn giản hơn, Logistics là một tập hợp các hoạt động xoay quanh hàng hóa như: đóng gói, bảo quản, vận chuyển hàng hóa ...

Dựa theo quá trình hoạt động, Logistics chia ra làm ba loại: Logistics đầu vào: Gồm những hoạt động mang tính "thu thập" như tiếp nhận và lưu trữ nguyên vật liệu 
đầu vào từ nhà cung cấp đến doanh nghiệp, đảm bảo rằng các yếu tố đầu vào được cung ứng một cách tối ưu về thời gian, giá trị và chi phí phục vụ cho quá trình sản xuất; Logistics đầu ra: Là các hoạt động liên quan đến việc dịch chuyển hàng hóa từ điểm cuối cùng của dây chuyền sản xuất đến khách hàng, thông qua các kênh phân phối (trực tiếp hoặc gián tiếp) đến tay người tiêu dùng; Logistic "ngược": Gồm các hoạt động của quá trình thu hồi lại sản phẩm lỗi, phế phẩm, phế liệu,... phát sinh sau khi phân phối sản phẩm để tái chế hoặc xử lý.

\section{Vai trò của Logistics}

Trong việc hoạt động kinh tế quốc tế, Logistics là công cụ liên kết các hoạt động trong chuỗi giá trị toàn cầu, đảm bảo hoạt động sản xuất kinh doanh đạt hiệu quả cao. Logistics phát triển góp phần mở rộng thị trường kinh doanh quốc tế. Hệ thống logistics có tác dụng như một chiếc cầu nối đưa hàng hóa đến các thị trường mới theo đúng yêu cầu về thời gian và địa điểm đặt ra. Nhờ đó, các nhà sản xuất kinh doanh có thể chiếm lĩnh thị trường cho sản phẩm của mình, đồng thời thị trường kinh doanh quốc tế cũng được mở rộng và phát triển. Mặt khác, các giao dịch quốc tế cần phải sử dụng nhiều loại giấy tờ, chứng thực rườm rà, làm tiêu tốn chi phí. Do đó, sự phát triển của Logistics sẽ tạo ra cuộc cách mạng về vận tải và dịch vụ, đồng thời chi phí, giấy tờ tài liệu trong quá trình luân chuyển hàng hóa cũng được giảm thiểu, các quốc gia sẽ xích lại gần nhau hơn trong hoạt động sản xuất và lưu thông. (Diễm, 2021)

Đối với nền kinh tế quốc dân, Logistics là một thành tố quan trọng đóng góp vào GDP, nó tác động tới việc mất giá đồng tiền, mức lãi ngân hàng, năng suất lao động, giá năng lượng và các lĩnh vực khác của nền kinh tế. Hiện nay, ở các nước phát triển như Nhật, Mỹ, chi phí Logistics chiếm 10-13\% GDP; đối với những nước đang phát triển thì khoảng $15 \%$ - 20\% GDP, Việt Nam là 25\% GDP, với nước kém phát triển tỷ lệ này có thể lên đến hơn 30\% GDP (Malco, 2015) . Có thể thấy chi phí logistics chiếm một khoản không nhỏ đối với nền kinh tế, nó tác động tới và chịu tác động bởi các hoạt động kinh tế khác. Một khi Logistics được phát triển sẽ làm giảm chi phí, đảm bảo về thời gian và chất lượng cho các hoạt động kinh tế khác.

Còn đối với doanh nghiệp, dịch vụ Logistics giúp giải quyết hiệu quả các yếu tố đầu vào và đầu ra của doanh nghiệp bằng cách tối ưu hóa việc vận chuyển nguyên vật 
liệu, hàng hóa dịch vụ ...; nâng cao hiệu quả quản lý, giảm chi phí trong quá trình sản xuất và phân phối hàng hóa, tăng khả năng cạnh tranh của doanh nghiệp, đồng thời tạo lợi thế về thời gian địa điểm việc phân phối tiêu thụ sản phẩm trong điều kiện thị trường tiêu thụ và nguồn cung ngày càng cách xa về mặt địa lý với xu hướng toàn cầu hóa hiện nay. Ngoài ra, dịch vụ Logistics còn giúp doanh nghiệp vận chuyển hàng hóa và cung cấp dịch vụ cho khách hàng một cách hiệu quả và nhanh chóng. Việc xây dựng các giải pháp tối ưu về lưu trữ, vận chuyển, thu mua... và phát triển hệ thống thông tin hiện đại sẽ là điều kiện tốt để đưa hàng hóa đến khách hàng với thời gian ngắn nhất. Cuối cùng, việc phát triển hệ thống Logistics hiệu quả tạo ra lợi thế cạnh tranh cho các công ty sản xuất và kinh doanh bằng cách bán hàng hóa với chi phí thấp hơn, danh tiếng của công ty cũng được củng cố thông qua việc cung cấp dịch vụ tốt hơn và toàn diện hơn cho khách hàng.

\section{Thực trạng ngành Logistics Việt Nam trước khi xuất hiện đại dịch covid-19 (trước năm 2020)}

Với quy mô 20-22 tỷ USD/năm, chiếm 20,9\% GDP của cả nước, theo một số thống kê, hiện nay cả nước có hơn 1000 doanh nghiệp đang cung ứng dịch vụ logistics, cùng với số lượng lao động lên đến khoảng 1,5 triệu, những năm gần đây, ngành dịch vụ Logistics đang đóng vai trò quan trọng trong quá trình hội nhập và phát triển kinh tế ở Việt Nam.

Sau nhiều năm Việt Nam gia nhập WTO, thị trường dịch vụ Logistics Việt Nam có sự chuyển biến tích cực với số lượng các doanh nghiệp hoạt động trong ngành phát triển nhanh và có tốc độ tăng trưởng cao. Nếu nhìn vào tốc độ phát triển thương mại nước ta, cũng là mục tiêu phát triển của ngành dịch vụ Logistics, sẽ thấy kim ngạch xuất nhập khẩu đã tăng lên 1,86 lần, thị trường bán lẻ trong nước tăng bình quân tăng 20$25 \% /$ năm và kết quả, ngành dịch vụ Logistics cũng tăng tương ứng 20-25\%/năm (BBT, 2016).

Tuy vậy, ngành Logistics Việt Nam đang phải đối mặt với rất nhiều thách thức và hạn chế: 
Về lao động: Thị trường lao động ngành Logistics Việt Nam khá dồi dào, nhưng đó lại là đối với các doanh nghiệp Nhà nước đang được cổ phần hoá, thực tế ở các doanh nghiệp vừa và nhỏ, nguồn nhân lực chỉ đáp ứng được khoảng $40 \%$ nhu cầu của ngành, tỷ lệ nguồn nhân lực được đào tạo bài bản về Logistics còn chiếm khá thấp, chỉ từ 5-7\% (BBT, 2016)

Về doanh nghiệp: Hiện nay, các doanh nghiệp lớn đang chiếm lĩnh thị trường nhiều, doanh nghiệp nhỏ chưa có chỗ đứng trên thị trường. Bên cạnh đó, theo thống kê cho thấy các công ty Logistics Việt Nam mới chỉ hoạt động trong phạm vi nội địa hay một vài nước trong khu vực, và chủ yếu làm đại lý hoặc đảm nhận từng công đoạn cho các doanh nghiệp Logistics quốc tế, thua thiệt ngay trên "sân nhà" đối với lĩnh vực được coi là ngành dịch vụ "cơ sở hạ tầng” của nền kinh tế Quốc gia.

Về cơ sở hạ tầng: Cơ sở vật chất chưa được trang bị những công cụ, phương tiện tốt nhất để vận chuyển hàng hóa. Hàng hóa vẫn thường bị ùn tắc rất nhiều và vẫn chưa có cách để xử lý ổn thỏa và triệt để nhất.

Về chi phí dịch vụ: Mức chi phí dịch vụ rất cao đang là vấn đề cần được cải thiện với ngành Logistics Việt Nam

Đồng thời, đi cùng với những thách thức là cơ hội phát triển của ngành Logistics Việt Nam. Hiện nay, ngành Logistics Việt Nam đã bắt đầu tiếp cận được thị trường logistics rộng lớn hơn với những ưu đãi thương mại để thúc đẩy tiêu thụ sản phẩm, dịch vụ; Bên cạnh đó, địa hình nước ta rất phù hợp để phát huy lợi thế địa lý - chính trị trong phát triển cơ sở hạ tầng logistics như phát triển cảng nước sâu, sân bay quốc tế, hệ thống đường sắt xuyên Á, các trung tâm Logistics; việc hội nhập logistics quốc tế cũng tạo cơ hội cho Việt Nam phát triển quan hệ đối tác, thị trường xuất khẩu được mở rộng, góp phần cơ cấu lại nền kinh tế và đổi mới mô hình tăng trưởng...

\section{Thực trạng ngành Logistics Việt Nam trong tình hình dịch covid-19}

Đầu năm 2020, khi đại dịch COVID-19 bùng phát đã gây nên tổn thất trầm trọng đến mọi mặt từ kinh tế, văn hoá, du lịch đến đời sống con người trên toàn cầu $(\mathrm{La}, 2020)$. Đặc biệt, đại dịch đã gây áp lực nặng nề lên khả năng sản xuất cũng như chuỗi cung ứng 
toàn cầu hay còn là ngành dịch vụ Logistic. Toàn bộ dây chuyền của ngành logistic đã bị ảnh hưởng nặng nề từ đại dịch, mọi hoạt động bị trì hoãn và chính dịch bệnh cũng tạo nên những thử thách không ngừng dành riêng cho ngành từ hiện tại và cả trong tương lai.

Chuỗi cung ứng đã bị đảo lộn và đứt gãy do đại dịch mà những hoạt động thuộc ngành Logistics - cốt lõi của chuỗi cung ứng cũng không tránh khỏi ảnh hưởng. Đối với thế giới nói chung, các dịch vụ vận tải như vận tải đường bộ, vận tải đường sắt hay vận tải hàng không bị thiệt hại nặng nề nhất. Vận tải biển có bị tác động nhẹ hơn bởi việc giữ vững cước phí, dù yêu cầu chuyên chở có giảm sút và khó khăn về thủ tục do đại dịch (khi phải có những giấy tờ xét nghiệm, chứng nhận an toàn sức khỏe,... mới được thông qua).

Các đặc điểm này của chuỗi cung ứng và dịch vụ logistics thế giới cũng đã thể hiện đầy đủ trong ngành dịch vụ Logistics Việt Nam, khi mà sự khó khăn trong lưu thông dây chuyền cung ứng ở nước ta cũng xảy ra trên mọi mặt trận. Nêu lên thực trạng tắc nghẽn trong chuỗi logistic tại Việt Nam được thể hiện rõ nhất ở đợt bùng phát COVID-19 thứ tư kéo dài suốt năm tháng qua, bà Nguyễn Thị Thành Thực - Chủ tịch Công ty Bagico Bắc Giang, Uỷ viên Ban chấp hành Hiệp hội Nông nghiệp số Việt Nam cho biết trong đợt dịch vừa qua, sự " ngăn sông cấm chợ” đã khiến cho 1 kg rau tại Bình Phước có giá 8 nghìn đồng, trong khi vẫn $1 \mathrm{~kg}$ rau đó tại thành phố Hồ Chí Minh người dân có thể phải mua tới 70-80 nghìn đồng. “ Đây chính là sư lãng phí rất lớn. Vấn đề ở đây là do cách điều hành, người dân nói chung hay bà con nông dân nói riêng bị thiệt hại, doanh nghiệp hay người tiêu dùng cũng đều chịu thiệt hại”, Trang nói tại tọa đàm. Điều này dẫn tới sự khủng hoảng cho người dân nói chung và các doanh nghiệp nói riêng về mặt tinh thần.. Qua đây, có thể thấy ngành Logistics trong giai đoạn vừa qua bị tác động bởi nhiều yếu tố tiêu cực ở cả nội địa và ngoài nước. Còn theo ông Lê Duy Hiệp - Chủ tịch Hiệp hội Doanh nghiệp Dịch vụ logistics Việt Nam, chuỗi cung ứng hoạt động không mấy hiệu quả và cũng chính là các doanh nghiệp đang phải chịu vô số tổn thất do đại dịch. Có rất nhiều doanh nghiệp đã phá sản, hay đang lâm vào tình trạng phá sản, rời bước khỏi thị trường lao động ngành logistic vì hậu quả nặng nề mà COVID19 đem lại. Việc doanh nghiệp phá sản cũng dẫn đến nguồn lao động bị ảnh hưởng, nhiều người trở nên thất nghiệp, nhiều công nhân bị mất việc khiến cho cuộc sống của 
họ và gia đình họ đã khó khăn nay càng khó khăn hơn. Ông Hiệp còn nói “ Sản lượng vận tải của ngành Logistics trong 6 tháng đầu năm 2021 so với 2020 không kém là bao. Nhưng đến tháng 7 , tháng 8 lại bị sụt giảm nghiêm trọng do các hạn chế trong quá trình vận chuyển, đồng thời bị thiếu hụt một phần lực lượng lao động” (Phượng, 2021).

Đối với ngành hàng không, các hãng hàng không hiện nay đều hủy tối đa các chuyến bay tới Hồng Kông, Trung Quốc, Hàn Quốc thêm vào đó hạn chế nhất có thể các chuyến bay từ vùng dịch. Ngoài ra, giá cước vận chuyển hàng hóa tăng cao hơn so với bình thường. Trong khi đó, các tuyến biên giới đều khó để kiếm được nhà cung cấp vận chuyển. Nhu cầu vận tải đường bộ giờ giảm xuống còn $30 \%$ do lượng hàng hoá sụt giảm. Ngành hàng không cũng đã chịu những tổn thất nặng về vô cùng lớn, ảnh hưởng kinh tế trầm trọng trong khi dịch bệnh vẫn hoành hành không có dấu hiệu giảm nhẹ. Bằng chứng là nhiều hãng hàng không đã phải vay nợ và xin hỗ trợ tài chính từ chính phủ, nhiều nhân viên, tiếp viên phải nghỉ việc hoặc buộc phải thôi việc do cắt giảm nhân sự bởi công ty không đủ ngân sách để chi trả lương. Qua đây, Logistic một lần nữa cho thấy vai trò quan trọng của mình đối với xã hội.

Những tổn thất nặng nề mà ngành đang phải hứng chịu khiến xương sống của chuỗi cung ứng ngày một trở nên “ kiệt sức “, tác động tiêu cực tới vô số ngành có liên quan. Ở một số khía cạnh khác trong ngành Logistics ở Việt Nam, các ngành sản xuất như dệt may dựa chủ yếu vào việc nhập khẩu nguyên liệu từ Trung Quốc - nơi xảy ra đại dịch mạnh nhất, đã ngưng trệ sản xuất. Chiến dịch giải cứu hàng hóa ở biên giới với Trung Quốc bị ách tắc trong giai đoạn đầu của đại dịch và đặc biệt là thời gian cách ly xã hội diễn ra từ tháng 4 đến tháng $8 / 2020$ đã làm cho những quy trình sản xuất, Logistics, vận tải bị tắc nghẽn, gián đoạn. Từ tháng 5/2021, kinh tế bắt đầu phục hồi nhưng đại dịch COVID-19 tiếp tục diễn biến phức tạp tại các thị trường là đối tác thương mại chính của Việt Nam do đó gây ảnh hưởng tiêu cực tới hoạt động xuất, nhập khẩu và Logistics. Nhu cầu quốc tế giảm sút đồng nghĩa với việc giảm xuất khẩu đơn hàng dẫn đến việc nhiều công ty buộc phải cho công nhân nghỉ việc.

Để tìm ra các giải pháp sáng tạo giúp giảm tổn thất nặng nề từ tác động của dịch COVID-19, từ cách tiếp cận tổng thể, chúng tôi khuyến nghị sử dụng hệ sáng tạo, hay còn gọi là hệ xử lý thông tin 3D (Vuong, Q.H., 2022; Vuong \& Napier, 2014). Trong hệ 
này, việc thu thập thông tin, xử lý thông tin truyền thông rất quan trọng. Tiếp theo là làm việc với các chuyên gia giỏi nhất trong ngành Logistics và hợp tác giữa các bên liên quan (nhà nước, doanh nghiệp, khác hàng, chuyên gia) một cách thường xuyên.

Tóm lại, đại dịch COVID-19 đã gây ra thiệt hại nặng nề cho tất cả các ngành trong thị trường lao động của Việt Nam và tất cả các quốc gia trên toàn thế giới. Đặc biệt trong số đó, Logistic đã và đang hứng chịu sự tàn phá di dịch bệnh, ảnh hưởng tới nhiều khía cạnh và vấn đề. Bên cạnh những khó khăn do dịch bệnh đem lại, Logistics Việt Nam cũng có những thời cơ mới để chuyển mình phát triển trong tương lai.

\section{TÀI LIỆU THAM KHẢO}

BBT. (2016). Co hội \& thách thức cho ngành Logistics Việt Nam trước ngương cưa hộ nhập sâu. ATM GLOBAL TRANS.

Diễm, N. (2021). Vai trò của logistics đối với hoạt động kinh tế quốc tế, nền kinh tế quốc dân và doanh nghiệp. Luật Minh Khuê.

La, V. P. et al. (2020). Policy response, social media and science journalism for the sustainability of the public health system amid the COVID-19 outbreak: The vietnam lessons. Sustainability (Switzerland), 12(7). https://doi.org/10.3390/su12072931

Malco. (2015). Vai trò và lợi ích của Logistics. Logistics4vn.

Phượng, T. (2021). Đại dịch COVID-19: doanh nghiệp logistics Việt Nam "thức tỉnh." Việt Báo.

Vuong, Q.H., et al. (2022). Covid-19 vaccines production and societal immunization under the serendipity-mindsponge-3D knowledge management theory and conceptual framework. Humanities \& Social Sciences Communications, 9, 22. Retrieved from: https://www.nature.com/articles/s41599-022-01034-6

Vuong, Q. H., \& Napier, N. K. (2014). Making creativity: the value of multiple filters in the innovation process. International Journal of Transitions and Innovation Systems, 3(4), 294-327. https://doi.org/10.1504/ijtis.2014.068306 